\title{
The origin of urinary aromatic compounds excreted by ruminants 2. The metabolism of phenolic cinnamic acids to benzoic acid
}

\author{
BY A. K. MARTIN \\ Hannah Research Institute, Ayr, Scotland KA6 5HL \\ (Received 12 January 1981-Accepted 14 August 1981)
}

1. The extent to which phenolic derivatives of benzoic acid (seven); of phenylacetic acid (one); of 3phenylpropionic acid (one) and of cinnamic acid (six) served as precursors of the urinary benzoic acid excreted by sheep was determined after administration as continuous drips via rumen or abomasal cannulas.

2. Phenolic derivatives of benzoic or of phenylacetic acid were not dehydroxylated to yield aromatic acids following administration via either route.

3. Rumen infusion of phenolic derivatives of both 3-phenylpropionic and cinnamic acids gave enhanced rumen concentrations of 3-phenylpropionic acid with negligible amounts of benzoic acid. Between 63 and $106 \%$ of the 2-, 3- or 4-hydroxy acids, of the 3,4-dihydroxy acids or of the 3-methoxy, 4-hydroxy acids infused were excreted in the urine as benzoic acid and a variable proportion, characteristic of the individual animal, of up to $20 \%$ of the dose as cinnamic acid.

4. Abomasal infusion of monohydroxy 3-phenylpropionic and cinnamic acids did not yield urinary benzoic acid increments. However, between 11 and $34 \%$ of abomasally-infused disubstituted phenolic cinnamic acids infused were excreted in the urine as benzoic acid due, it is postulated, to entero-hepatic circulation and microbial metabolism of the infused acids in the large intestine.

5. It is concluded that rumen microbial metabolism of dietary phenolic cinnamic acids to 3-phenylpropionic acid followed by its absorption and oxidation in the body tissues is responsible for the greater part of the benzoic and cinnamic acids found in ruminant urine.

Ruminants may excrete large quantities of aromatic acids in their urine; outputs of $1475 \mathrm{mg}$ benzoic acid equivalent (BAE)/ $\mathrm{kg}$ body-weight ${ }^{0.75}$ per $24 \mathrm{~h}$ have been reported. This output may be compared with urinary aromatic acid outputs of between 14 and $115 \mathrm{mg}$ BAE/ $\mathrm{kg}$ body-weight $\mathrm{t}^{\mathbf{7 5}}$ per $24 \mathrm{~h}$ by man, rats, rabbits or dogs (Martin, 1969). Benzoic acid (BA) is the principal aromatic acid in ruminant urine and studies in this laboratory have suggested that dietary consitutents which yield 3-phenylpropionic acid (3-PPA) on rumen fermentation are important precursors (Martin, 1982).

3-PPA is the major aromatic acid found in the rumen fluid of steers (Cmelik \& Mathews, 1965), of sheep (Scott et al. 1964; Martin, 1973, 1982) and of cows (Patton \& Kesler, 1967); only trace amounts of BA are found. Tyrosine is metabolized to a limited extent in the rumen to yield 3-PPA (Scott et al. 1964; Patton \& Kesler, 1967) but both these studies showed that the amounts of 3-PPA that were found in rumen fluid were too great to be accounted for by rumen microbial metabolism of tyrosine.

As 3-PPA is not found in ruminant forages microbial metabolism of other components must occur. Phenolic cinnamic acid derivatives occur in combined form in all higher plants (Harborne \& Simmonds, 1964). Studies reported in this paper show that six of the naturally-occurring phenolic cinnamic acids are metabolized in the rumen to 3-PPA which yielded urinary increments in BA excretion equivalent to between 63 and $86 \%$ of the dose given. Administration of naturally occurring phenolic benzoic acids did not increase the normal urinary BA output of sheep.

\section{EXPER I M EN T A L}

Experimental design. Details of the sheep with rumen and abomasal cannulas which were used, the rations they were given, the collection of faeces and urine and experimental procedures have been described previously (Martin, 1982). 
Phenolic compounds infused. Thirty-four rumen and sixteen abomasal infusions were made. The substances infused were the purest available and except where noted were infused as received. British Drug Houses Ltd, Poole, Dorset supplied salycylic (2OH-BA); 3hydroxybenzoic $(3 \mathrm{OH}-\mathrm{BA})$; gentisic $(2,5 \mathrm{OH}-\mathrm{BA})$; protocatechnic $(3,4 \mathrm{OH}-\mathrm{BA}$, recrystallized); vanillic ( $3 \mathrm{MeO}, 4 \mathrm{OH}-\mathrm{BA})$ and gallic (3,4,5OH-BA) acids, casein (light white soluble) and orcinol; Fluorochem (Fluka), Glossop, Derbyshire supplied rutin; Koch-Light Ltd, Colnbrook, Bucks supplied o-coumaric (2OH-CA); ferulic (3MeO,4OH-CA); phoretic (4OH-3PPA) and 4-hydroxybenzoic (4OH-BA) acids and $p$-arbutin and the Aldrich Chemical Co. Ltd, Gillingham, Dorset suppled $m$ - and $p$-coumaric (3OH-CA and $4 \mathrm{OH}-\mathrm{CA}$ respectively); caffeic (3,4OH-CA) and 4-hydroxyphenylacetic (4OH-PA) acids.

Chlorogenic acid (CHL; 3-0-caffeoyl-quinic acid) was isolated from green coffee beans as described by Moores et al. (1948). Three samples of coffee beans were used which contained between 42 and $71 \mathrm{~g} \mathrm{CHL} / \mathrm{kg}$ fresh weight.

When experimental periods were of more than $24 \mathrm{~h}$ duration (i.e. in Expts 1,5 and 6 in which QA, CHCA, BA, 2OH-BA, 3,4OH-BA, CA, 2OH-CA, 3OH-CA, 4OH-CA, 3,4OH-CA, 3MeO,4OH-CA or CHL were infused; Tables 1 and 2, Martin, 1982) the u.v. absorbance of samples of the infusion solution was determined daily. The absorbance of 200 to 500 -fold dilutions was recorded between 350 and $220 \mathrm{~nm}$ (SP800 spectrophotometer; Pye Unicam Ltd, Cambridge). All acids were recrystallized twice from water and the following $\lambda_{\max }$ and $\epsilon$ values (in parentheses) found: $2 \mathrm{OH}-\mathrm{BA} \mathrm{Na}{ }^{+}$salt, $230 \mathrm{~nm}(6500)$; $3,4 \mathrm{OH}-\mathrm{BA}, 254 \mathrm{~nm}(7620)$; $3 \mathrm{OH}-\mathrm{CA} \mathrm{Na}{ }^{+}$salt, $271 \mathrm{~nm}(16760) ; 2 \mathrm{OH}-\mathrm{CA} \mathrm{Na}{ }^{+}$salt, $269 \mathrm{~nm}$ (14580); 4OH-CA Na ${ }^{+}$salt, $284 \mathrm{~nm}(19200) ; 3,40 H-C A \mathrm{Na}^{+}$salt, $286 \mathrm{~nm}$ (14920); $3 \mathrm{MeO}, 4 \mathrm{OH}-\mathrm{CA} \mathrm{Na}{ }^{+}$salt, $286 \mathrm{~nm}$ (14070); CHL, $324 \mathrm{~nm}$ (18340). Infusions were prepared by dissolving the acids in deoxygenated water (boiled and bubbled with nitrogen) and addition when required of exactly the amount of sodium hydroxide needed to neutralize the added acid. The solutions to be infused were kept out of direct sunlight but not in the dark. No change was found in the a'ssorbance of any of the infusion solutions between preparation and the end of the infusion period $(5 \mathrm{~d})$. The amounts of acids infused are given in Tables 1 and 2.

Urine analyses. Daily creatinine output and outputs of aromatic acid glycine conjugates, diethyl ether- and toluene-soluble acids of hydrolysed urine and the aromatic acids in toluene extracts of hydrolysed urine were determined as described previously (Martin, 1982).

The assay of urinary aromatic acid glycine conjugates by gas-liquid chromatography of their methyl esters enabled additionally the determination of the urinary output of some free phenolic acids. The relative retentions of their methyl esters to the heneicosanoic acid internal standard used were: $3 \mathrm{MeO}, 4 \mathrm{OH}-\mathrm{BA} 0 \cdot 38,3 \mathrm{OH}-\mathrm{BA} 0.62,4 \mathrm{OH}-\mathrm{PA} 0 \cdot 79,4 \mathrm{OH}-\mathrm{BA}$ $0 \cdot 80,3,4,5 \mathrm{OH}-\mathrm{BA} 0 \cdot 84$. Peak areas relative to the internal standard were determined by triangulation.

Aromatic acids in rumen fluid. These were determined as described previously (Martin, 1982). Sheep nos. 5 and 6 were sampled when 3,4OH-CA and $3 \mathrm{MeO}, 4 \mathrm{OH}-\mathrm{CA}$ were infused, sheep no. 6 only when 2OH-CA, 3OH-CA and CHL were infused and sheep 5 and 7 when $3 \mathrm{OH}-\mathrm{CA}$ was infused.

In Expt no. 7 (tables 1 and 2; Martin, 1982) the total aromatic acids present in the rumen of sheep no. 12 which had been fasted for $10 \mathrm{~d}$ and in the rumens and caeca of three goats which had not been fasted were determined. The animals were killed, their rumens and caeca tied-off and the contents weighed. The digesta were then freeze-dried in the centrifugal drum of a freeze-drier (Model 30 P2/796, Edwards Ltd, Crawley, Sussex) for $72 \mathrm{~h}$ and the dry yield weighed. Portions $(10 \mathrm{~g})$ of the dried contents were extracted for $16 \mathrm{~h}$ with toluene in a Soxhlet extraction apparatus and the combined toluene extracts concentrated to $250 \mathrm{ml}$. The total dry weights extracted were $80 \mathrm{~g}$ for rumen samples and $30-60 \mathrm{~g}$ for caecal samples. 
The toluene extracts were washed three times with 0.5 vol. sodium bicarbonate $(50 \mathrm{~g} / 1)$, the bicarbonate phase acidified to $\mathrm{pH} 1$ with hydrochloric acid and extracted three times with $1.0 \mathrm{vol}$. diethyl ether. Aromatic acids in the diethyl ether extract were determined using the method described for Expt 1 (Martin, 1982).

\section{RESULTS}

The output of urinary acids in control periods

The results obtained in the control periods of the five experiments in which phenolic acids were infused (Expts 2-6 inclusive, Table 3, Martin, 1982) and also in the control period of Expt 7 in which a sheep was subsequently fasted for $10 \mathrm{~d}$ have been reported; the calculation of the increments in urinary aromatic acid output in experimental periods was also described.

\section{Infusion of phenolic benzoic or phenylacetic acids}

No increments in urinary non-phenolic aromatic acids were found after rumen or abomasal infusion of the following phenolic acids: $2 \mathrm{OH}-\mathrm{BA} ; 3 \mathrm{OH}-\mathrm{BA} ; 4 \mathrm{OH}-\mathrm{BA} ; 3,4 \mathrm{OH}-\mathrm{BA}$; 2,5OH-BA; $3 \mathrm{MeO}, 4 \mathrm{OH}-\mathrm{BA} ; 3,4,5 \mathrm{OH}-\mathrm{BA}$ or $4 \mathrm{OH}-\mathrm{PA}$.

\section{Infusion of phenolic 3-phenylpropionic and cinnamic acids}

Four monohydroxyphenolic acids were infused ruminally (eleven determinations) or abomasally (five determinations) (see table 1, Martin, 1982) and the resulting increments in urinary aromatic acid output are summarized in Table 1. Phenolic acid assays made in Expt 4 showed urinary excretion of free $4 \mathrm{OH}-\mathrm{BA}$ only after abomasal infusion of either $4 \mathrm{OH}-3 \mathrm{PPA}(9 \%$ of the dose) or $4 \mathrm{OH}-\mathrm{CA}(18 \%$ of the dose); no free $4 \mathrm{OH}-\mathrm{BA}$ was excreted after rumen infusion of these acids.

Three disubstituted phenolic cinnamic acids were infused ruminally (eleven determinations) or abomasally (four determinations) and the resulting increments in urinary aromatic acids are summarized in Table 2.

Sheep no. 6 (Expt 5) excreted $7.2 \%$ of ruminally infused cinnamic or phenolic cinnamic acids $(n 6)$ in its urine as 3-PPA plus CA. This was a significantly $(P<0.01)$ greater increment than that found when sheep no. $5(2.5 \%)$ or no. $6(2.7 \%)$ received rumen infusions of the same acids: the standard error of the mean percentage of infused acids excreted as 3-PPA plus CA by sheep nos. 5, 6 and 7 was $0 \cdot 78$. No similar between sheep differences were found in urinary benzoic acid output after infusion of phenolic cinnamic acids.

\section{Aromatic acids in rumen fluid}

Rumen infusion of $2 \mathrm{OH}-\mathrm{CA}, 3 \mathrm{OH}-\mathrm{CA}, 4 \mathrm{OH}-\mathrm{CA}, 3,4 \mathrm{OH}-\mathrm{CA}, 3 \mathrm{MeO}, 4 \mathrm{OH}-\mathrm{CA}$ and $\mathrm{CHL}$ all resulted in increased concentrations of 3-PPA in rumen fluid (Fig. 1). No changes in the concentrations of $\mathrm{BA}$ or of PA were found on infusion of these acids or after rumen infusion of $2 \mathrm{OH}-\mathrm{BA}$ or $3,4 \mathrm{OH}-\mathrm{BA}$. Infusion of $\mathrm{CHL}$ caused cyclohexanecarboxylic acid increments of 0.5 to $0.9 \mathrm{mg} \mathrm{BAE} / 1$ rumen fluid per $\mathrm{g} B \mathrm{BE}$ infused as quinic acid moiety in $24 \mathrm{~h}$. After rumen infusions of phenolic cinnamic acids the increase in rumen 3-PPA concentration was (mean $\pm \mathrm{SD} ; n$ 39) $9 \cdot 6 \pm 2.6 \mathrm{mg}$ BAE/l rumen fluid per $\mathrm{g}$ BAE infused in $24 \mathrm{~h}$.

The rumen contents of a sheep (no. 12, Expt 7, Martin, 1982) which had been fasted for $10 \mathrm{~d}$ yielded $150 \mathrm{~g}$ dry matter which contained no detectable BA, $3 \mathrm{mg}$ PA and $0.4 \mathrm{mg} 3$-PPA. In contrast the dry rumen contents $(340 \mathrm{~g})$ of a fed 3 -year-old male goat contained $28 \mathrm{mg}$ PA and $545 \mathrm{mg}$ 3-PPA. The caecal contents of three goats (34-57 g dry matter) contained between 0.1 and $1.7 \mathrm{mg} \mathrm{BA}$, between 6 and $33 \mathrm{mg} \mathrm{PA}$ and between 1 and $10 \mathrm{mg}$ 3-PPA. Aromatic acids were not completely recovered on freeze-drying rumen contents so these 


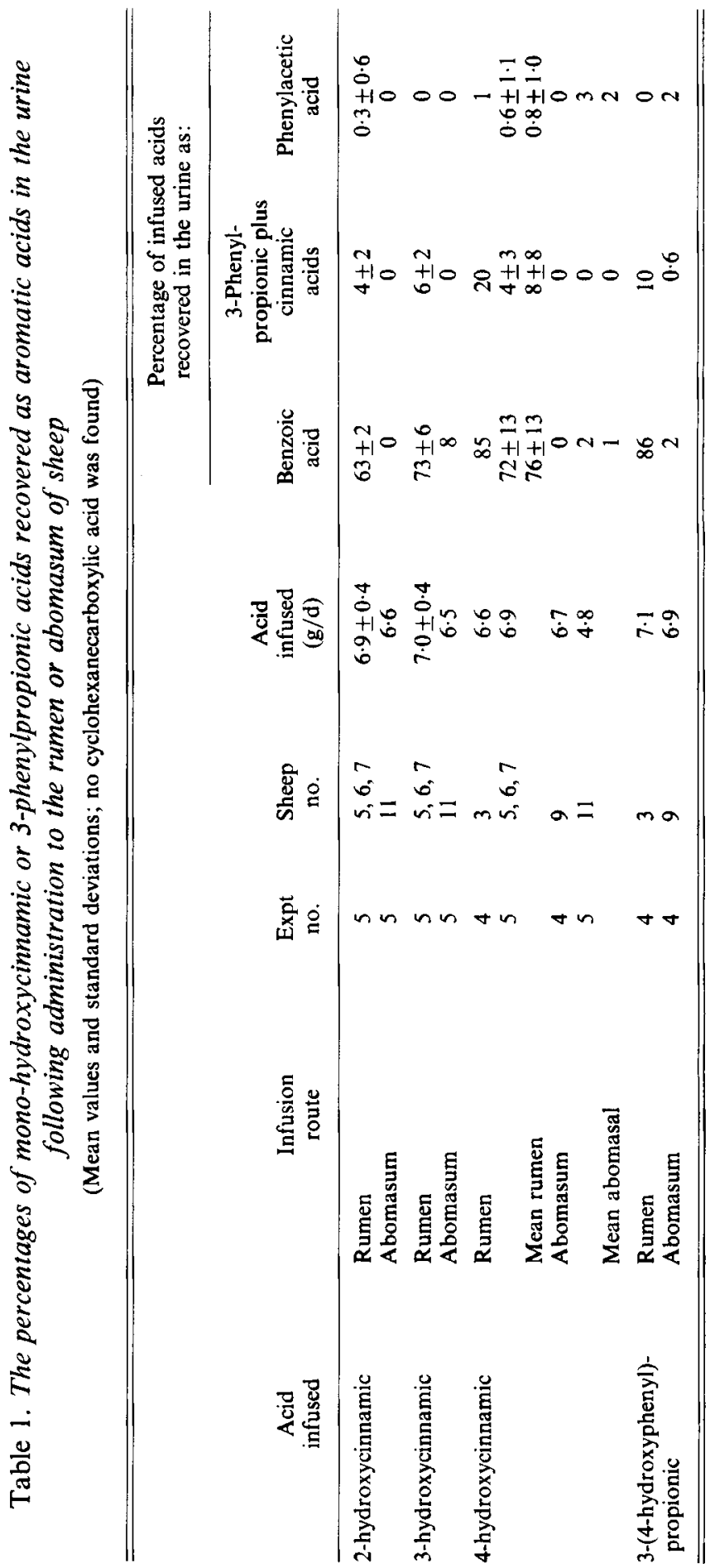









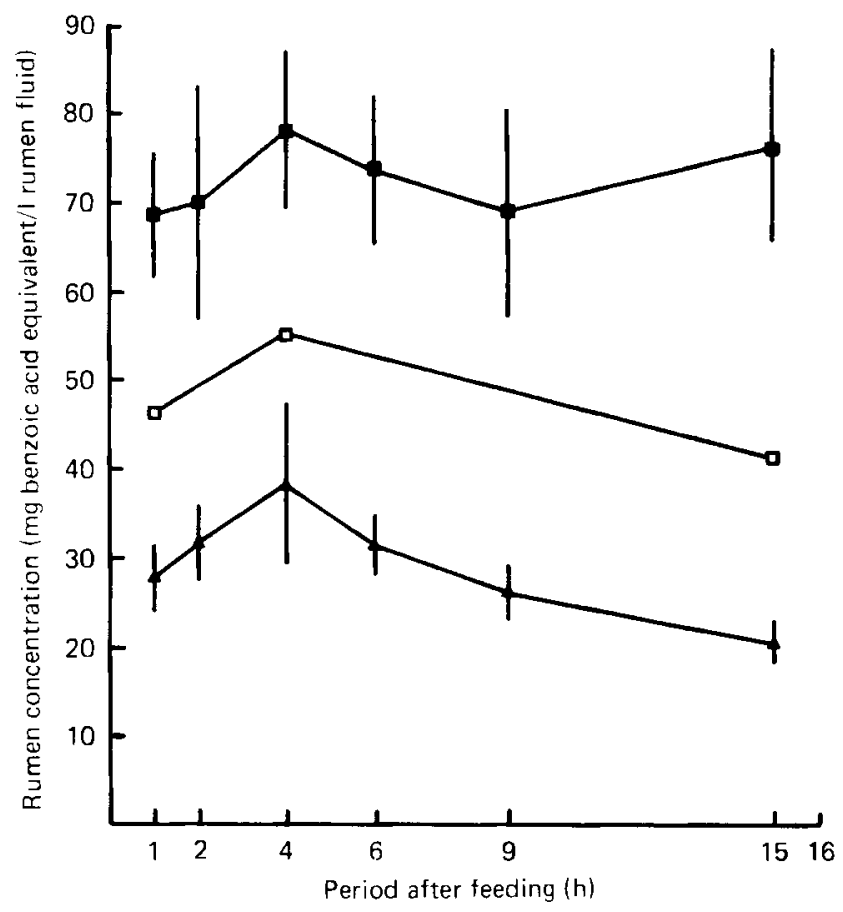

Fig. 1. The mean concentrations of 3-phenylpropionic acid in rumen fluid in relation to time of feeding in control periods and when rumen infusions of phenolic cinnamic acids were made: (A), control periods ( $n$ 9); ( $\square$ ), chlorogenic acid infusion in which 1.5 or $1.8 \mathrm{~g}$ of benzoic acid equivalent infused was derived from the 3,4-hydroxycinnamic acid moiety $(n 2)$; ( $\square$ ), 2-hydroxycinnamic $(n 1)$, 3-hydroxycinnamic $(n$ 2), 4-hydroxycinnamic ( $n$ 1), 3,4-hydroxycinnamic $(n 2)$ and 3-methoxy,4-hydroxycinnamic $(n 2)$ acid infusions in which $4.8 \pm 0.5 \mathrm{~g} / \mathrm{d}$ of benzoic acid equivalent was infused. Rumen fluid samples were taken in Expts 5 and 6 (Martin, 1982); in Expt 5 samples were only taken at 1, 4 and 15 h after feeding. Points are mean values with one standard deviation represented by vertical bars.

amounts are minimal estimates; recovery of phenylacetic acid added to rumen fluid and freeze-dried was only $20 \%$.

\section{DISCUSSION}

These experiments have shown rumen microbial metabolism to be responsible for the metabolism of dietary phenolic cinnamic acids to urinary BA (63-106\% of acids infused) and 3-PPA plus CA (4-20\% of acids infused). Scheline (1978) has summarized recent studies of the metabolism of phenolic acids by man and laboratory animals. The principal reactions of phenolic cinnamic acids mediated by the intestinal microflora are: reduction of the unsaturated aliphatic side-chain; demethylation of methoxy-subsituted phenolic acids; dehydroxylation and decarboxylation.

Microbial biohydrogenation of unsaturated fatty acids is well known (e.g. Wilde \& Dawson, 1966) and Scheline (1968) has found phenolic cinnamic acids to be reduced to the corresponding phenolic 3-phenylpropionic acid by the microflora of the rat caecum. Demethylation of phenolic methoxy groups is a reaction largely confined to the microflora of the intestine (Meyer \& Scheline, 1972). Both dehydroxylation and decarboxylation depend on the nature of the parent aromatic acid and on the position of hydroxylation in the aromatic ring. Phenolic benzoic acids were not subject to microbial dehydroxylation in the present experiments; Dacre \& Williams (1968) have made similar observations on phenolic benzoic acid metabolism in the rat intestine. In contrast $3,4 \mathrm{OH}-\mathrm{PA}$ and $3,4 \mathrm{OH}-\mathrm{CA}$ 
are extensively dehydroxylated in the 4-position by the rat caecal microflora (Scheline, 1968); the metabolism of the resulting 3-hydroxy phenolic acids was not studied. The intestinal microflora of sheep (Scott et al. 1964) and of man (Curtius et al. 1976) can dehydroxylate 4OH-3PPA to 3-PPA. The present experiments provide the first evidence for extensive dehydroxylation of 2-and 3-hydroxy 3-phenylpropionic and cinnamic acids. Most previous studies only considered phenolic metabolites (e.g. Booth \& Williams, 1963; Scheline, 1968).

The nature of the parent aromatic acid as it affects microbial decarboxylation of phenolic acids determines the large urinary output of benzoic acid characteristic of ruminants. Neither the intestinal microflora of man (Curtius et al. 1976) nor that of the rat (Scheline, 1968) can decarboxylate 4OH-3PPA; Finkle et al. (1962) have found that the decarboxylases of Aerobacter species to be active with 4OH-CA but inactive with 4OH-3PPA. By contrast 4OH-BA and 4OH-PA (Scheline, 1978) and 4OH-CA (Peppercorn \& Goldman, 1971) are extensively decarboxylated by rumen micro-organisms. All phenolic acids subject to microbial decarboxylation possess a 4-hydroxy substituent. Significant amounts of decarboxylation products were not found after rumen infusion of phenolic cinnamic acids in the present experiments (Martin, unpublished results). This suggests that the rate of side-chain biohydrogenation exceeds that of decarboxylation leading to phenolic 3-phenylpropionic acid products which cannot be decarboxylated.

Intestinal micro-organisms readily hydrolyse chlorogenic acid to $3,4 \mathrm{OH}-\mathrm{CA}$ and quinic acid (Scheline, 1973). The small combined BA and 3-PPA plus CA increment following rumen infusion of $\mathrm{CHL}(48 \%$, Table 2$)$ was probably due to a low yield of BA from the quinic acid moiety (Martin, 1982).

The extent of phenolic substitution in the aromatic ring determined the nature of the urinary metabolites excreted after abomasal infusion of phenolic cinnamic acids. Monophenolic acids did not yield urinary increments of non-phenolic aromatic acids (Table 1) whereas diphenolic acids did yield small increments (11-34\%, Table 2). Within the body tissues the principal reactions of phenolic cinnamic acids are methylation of phenolic hydroxyl groups (Scheline, 1978) and $\beta$-oxidation (Ranganathan \& Ramasarma, 1974). Hydration of the side-chain during $\beta$-oxidation is thought to yield phenylhydracrylic and phenyllactic acids, the latter on oxidation yielding a phenolic phenylacetic acid (Scheline, 1978). On abomasal infusion of phenolic cinnamic acids a variety of phenolic BA, PA, 3-PPA and CA metabolites may be expected either free or as conjugates of amino acids, sulphate or glucuronic acid. In the present experiments $4 \mathrm{OH}-\mathrm{BA}$ as a $\beta$-oxidation product equivalent to up to $18 \%$ (Expt 4 ) of abomasally-infused phenolic cinnamic acids was observed; failure to detect phenolic benzoic acids following rumen infusion confirms that rumen dehydroxylation was extensive.

Disubstituted phenolic acids are able to form glucuronides in body tissues; biliary excretion of these compounds followed by microbial hydrolysis of the conjugate and metabolism of the aglycone to 3-PPA in the caecum is the most likely cause of the increments in urinary BA found on abomasal infusion of these acids in the present experiments (Scheline, 1978). Millburn (1970) has reviewed factors influencing biliary excretion of organic anions: those with a molecular weight in excess of 500 were readily excreted in the bile of all species; those with a molecular weight of between 300 and 500 were excreted to a lesser extent, the sheep being classified as an intermediate biliary excreter with $5-15 \%$ of a dose of such compounds being excreted by this route. The molecular weights of $3,4 \mathrm{OH}-\mathrm{CA}$; $3 \mathrm{MeO}, 4 \mathrm{OH}-\mathrm{CA}$ and of $\mathrm{CHL}$ are 356,370 and 530 respectively; the percentages of these acids excreted in the urine as BA, 3-PPA and CA after abomasal infusion were 23, 11 and $34 \%$ respectively (see Table 2 ). The presence of 3-PPA in the caeca of goats provides further evidence for the entero-hepatic circulation of phenolic cinnamic acids.

Do ruminant foods contain sufficient quantities of phenolic cinnamic acids to enable 


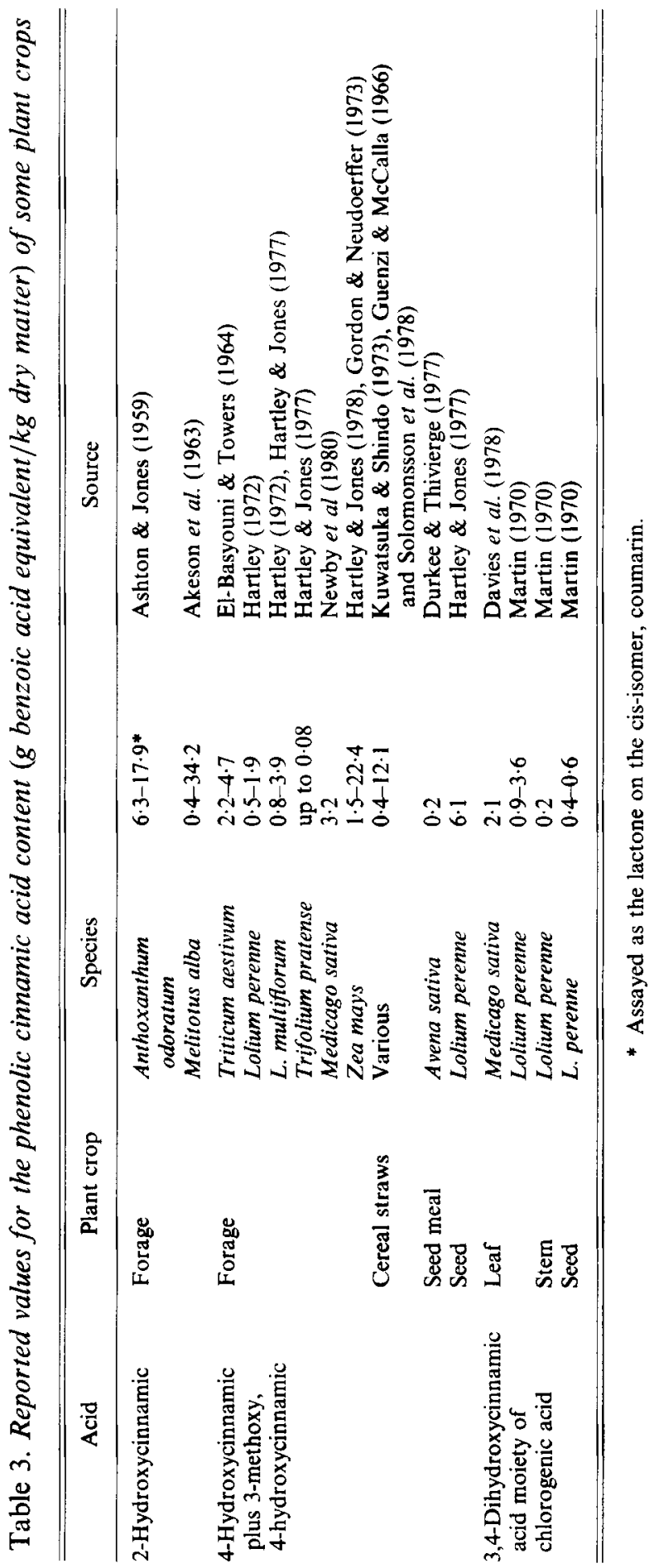


rumen metabolism to account for the quantities of benzoic acid excreted? Negligible amounts of the phenolic cinnamic acids found in plants exist in the tissues as free acids (Gorz \& Haskins, 1964; El-Basyouni \& Towers, 1964; Durkee \& Thivierge, 1977; Salomonsson et al. 1978); they occur in a variety of conjugated forms some of which are soluble and readily isolated and some of which are insoluble and require for their isolation hydrolytic procedures which may partially destroy the liberated acids (Newby et al. 1980). Soluble conjugates include the $\beta$-glucoside of $2 \mathrm{OH}-\mathrm{CA}$ which is found in large amounts in a limited number of ruminant forages (Haskins \& Gorz, 1961) and the more common 3,4OH-CA conjugates, the principal one being $\mathrm{CHL}$ (Harborne, 1964). Insoluble conjugates of $4 \mathrm{OH}-\mathrm{CA}$ and $3 \mathrm{MeO}, 4 \mathrm{OH}-\mathrm{CA}$ occur in most ruminant foods. Values for these phenolic acids in some foods are summarized in Table 3. Difficulties of quantitative isolation and the possible interaction of phenolic compounds with other plant constituents (Davies et al. 1978) mean that the quantities listed in Table 3 must be minimal estimates.

The smallest quantities of phenolic acids required in the foods used in the present experiments to account for all of the observed urinary BA, 3-PPA and CA outputs during control periods can be calculated from Tables 1 and 2 of the previous paper (Martin, 1982). Between $3.2 \mathrm{~g}$ (sheep no. 5, Expt 6; hay-sugar beet pulp ration) and $10.6 \mathrm{~g}$ (sheep no. 2, Expt 2; dried grass ration) of BAE/ $\mathrm{kg}$ food dry matter would have been required. Had forages whose $2 \mathrm{OH}-\mathrm{CA}$ concentration (see Table 3 ) was at the upper end of the reported range been offered in the present experiments control urinary aromatic acid outputs could have been much greater than those observed. The reported concentrations of the other phenolic cinnamic acids in Table 3 suggest that their rumen fermentation can account for a substantial proportion of the relatively large urinary BA and CA outputs of ruminants. The BA conjugates (Patton, 1953; Brewington et al. 1974) and CA (Parks \& Allen, 1961) found in cow's milk must have a similar origin.

The author is indebted to Mrs J. T. Knox, Mr R. Miller and Mrs J. Quig for technical assistance. Mr C. Park was in charge of the experimental animals.

\section{REFERENCES}

Akeson, W. R., Gorz, H. J. \& Haskins, F. A. (1963). Crop Sci. 3, 167.

Ashton, W. M. \& Jones, E. (1959). J. Br. Grassld Soc. 14, 47.

Booth, A. N. \& Williams, R. T. (1963). Nature, Lond. 198, 684.

Brewington, C. R., Parks, O. W. \& Schwartz, D. D. (1974). J. agric. Fd Chem. 22, 293.

Cmelik, S. H. W. \& Mathews, R. J. (1965). Rhodesia, Malawi \& Zambia J. agric: Res. 3, 95.

Curtius, H. Ch., Mettler, M. \& Ettlinger, L. (1976). J. Chromat. 126, 569.

Dacre, J. C. \& Williams, R. T. (1968). J. Pharm. Pharmac. 20, 610.

Davies, A. M. C., Newby, V. K. \& Synge, R. L. M. (1978). J. Sci. Fd Agric. 29, 33.

Durkee, A. B. \& Thivierge, P. A. (1977). J. Fd Res. 42, 551.

El-Basyouni, S. Z. \& Towers, G. H. N. (1964). Can. J. Biochem. 42, 203.

Finkle, B. J., Lewis, J. C., Corse, J. W. \& Lundin, R. E. (1962). J. biol. Chem. 237, 2926.

Gordon, A. J. \& Neudoerffer, T. S. (1973). J. Sci. Fd Agric. 24, 565.

Gorz, H. J. \& Haskins, F. A. (1964). Crop Sci. 4, 193.

Guenzi, W. D. \& McCalla, T. M. (1966). Agronomy J. 58, 303.

Harborne, J. B. (1964). In Biochemistry of Phenolic Compounds, p. 149 [J. B. Harborne, editor]. London: Academic Press.

Harborne, J. B. \& Simmonds, N. W. (1964). In Biochemistry of Phenolic Compounds, p. 83 [J. B. Harborne, editor]. London: Academic Press.

Hartley, R. D. (1972). J. Sci. Fd Agric. 23, 1347.

Hartley, R. D. \& Jones, E. C. (1977). Phytochemistry 16, 1531.

Hartley, R. D. \& Jones, E. C. (1978). J. Sci. Fd Agric. 29, 777.

Haskins, F. A. \& Gorz, H. J. (1961). Crop Sci. 1, 320.

Kuwatsuka, A. \& Shindo, H. (1973). Soil Sci. Plant Nutr. 19, 219.

Martin, A. K. (1969). Br. J. Nutr. 23, 389.

Martin, A. K. (1970). J. Sci. Fd Agric. 21, 496.

Martin, A. K. (1973). Br. J. Nutr. 30, 251. 
Martin, A. K. (1982). Br. J. Nutr. 47, 139.

Meyer, T. S. \& Scheline, R. R. (1972). Xenobiotica 2, 391.

Millburn, P. (1970). In Metabolic Conjugation and Metabolic Hydrolysis, vol. 2, pp. 28 and 59 [W. H. Fishman, editor]. London: Academic Press.

Moores, R. G., McDermott, D. L. \& Wood, L. R. (1948). Analyt. Chem. 20, 620.

Newby, V. K., Sablon, R.-M., Synge, R. L. M., Casteele, K. V. \& Van Sumere, C. F. (1980). Phytochemistry 19, 651.

Parks, O. W. \& Allen, C. (1961). J. Dairy Sci. 56, 328.

Patton, S. (1953). J. Dairy Sci. 36, 943.

Patton, S. \& Kesler, E. M. (1967). J. Dairy Sci. 50, 1505.

Peppercorn, M. A. \& Goldman, P. (1971). J. Bact. 108, 996.

Ranganathan, S. \& Ramasarma, T. (1974). Biochem. J. 140, 517.

Salomonsson, A.-C., Theander, O. \& Åman, P. (1978). J. agric. Fd Chem. 26, 830.

Scheline, R. R. (1968). Acta pharmac. tox. 26, 189.

Scheline, R. R. (1973). Pharmac. Rev. 25, 466.

Scheline, R. R. (1978). Mammalian Metabolism of Plant Xenobiotics, pp. 170-228. London: Academic Press.

Scott, T. W., Ward, P. F. V. \& Dawson, R. M. C. (1964). Biochem. J. 90, 12.

Wilde, P. F. \& Dawson, R. M. C. (1966). Biochem. J. 98, 469. 